\title{
Analysis of Energy Intensity Developments in Manufacturing Sectors in Industrialized and Developing Countries
}

\author{
A. Miketa
}

RR-02-006

September 2002

Reprinted from Energy Policy 29 (2001) 769-775.

International Institute for Applied Systems Analysis - Schlossplatz 1 - A-2361 Laxenburg • Austria Tel: (+43 2236) 807 • Fax: (+43 2236) 71313 • E-mail: publications@iiasa.ac.at •Web: www.iiasa.ac.at 
Research Reports, which record research conducted at IIASA, are independently reviewed before publication. Views or opinions expressed herein do not necessarily represent those of the Institute, its National Member Organizations, or other organizations supporting the work.

Reprinted from Energy Policy 29 (2001) 769-775, with permission from Elsevier Science.

Copyright (C 2001 Elsevier Science Ltd.

All rights reserved. No part of this publication may be reproduced or transmitted in any form or by any means, electronic or mechanical, including photocopy, recording, or any information storage or retrieval system, without permission in writing from the copyright holder. 


\title{
Analysis of energy intensity developments in manufacturing sectors in industrialized and developing countries
}

\author{
A. Miketa* \\ Graduate School of Media and Governance, Keio University at Shonan Fujisawa Campus, Japan \\ Environmentally Compatible Energy Strategies Project, International Institute for Applied Systems Analysis, A-2361 Laxenburg, Austria.
}

Received 18 January 2001

\begin{abstract}
This paper studies the development of energy intensity over time and its relationship with the sectoral economic development. Three variables are analyzed with respect to their impact on energy intensity; total sectoral economic activity, sectoral gross fixed capital formation and industrial energy prices. Panel analysis was conducted for ten manufacturing industries using pooled data of 39 countries between 1971 and 1996. This study finds that capital formation has the effect of increasing energy intensity and this effect is stronger where sectoral output is larger. The innovative value of this study deals with a large number of countries and describes in detail the manufacturing industries for which empirical evidence is provided. Another focus of this study is on the generation of an industrial energy intensity database which includes estimates of industrial energy prices for different countries. The database includes most of the Organization for Economic Cooperation and Development countries as well as other countries in Asia and Latin America. (C) 2001 Elsevier Science Ltd. All rights reserved.
\end{abstract}

Keywords: Sectoral energy intensity; Panel analysis; Manufacturing sectors

\section{Introduction}

In this paper, energy intensity at a sub-aggregated industry sectoral level is analyzed using panel data of 39 countries for the time period between 1971 and 1996. Particular attention has been paid to its relationship with a sectoral industrial development. The analysis is based on data of most of the Organization for Economic Cooperation and Development (OECD) countries as well as other countries in Asia and Latin America.

Energy intensity is important for many reasons, one of them being the obvious importance for the environment. One can view the relationship between overall economic activity and carbon dioxide $\left(\mathrm{CO}_{2}\right)$ emissions as the product of $\mathrm{CO}_{2}$ intensity of energy, energy intensity of economic activity and structure of economic activity in an economy. If one would wish to continue the expansion of global economic activity, these factors would be crucial in any effort to mitigate the impact of economic activity on carbon emissions. In particular, given the wide inter-

\footnotetext{
* Corresponding author. Tel.: + 43-2236-807-376; fax: + 43-2236807-488.

E-mail address: miketa@iiasa.ac.at (A. Miketa).
}

national gap in $\mathrm{CO}_{2}$ and energy intensities, efforts to narrow this gap appear to be a sound policy target. The importance of energy-efficiency improvement for energy-economy model results has been illustrated, among others, by Repetto and Austin (1997).

Despite the importance of the subject, there have been few quantitative comparitive studies of energy intensity. International variations in energy intensity are best understood as the consequence of the different technologies used in individual countries. Ideally, different energy intensities can be analyzed effectively if energy intensity is described as the result of the choice of different technologies. Such an approach has been quite successful in studies of the energy-converting industry (for instance, Messner and Strubegger, 1995). Some energy models are equipped with a detailed database of energy-converting technologies with some additional information on engineering artifacts. The mechanism that chooses from those technologies is formulated in these energy models and the resulting energy intensity is obtained as the model solution. For all other industry sectors, it is difficult to introduce such detailed descriptions of the technologies into models, because of their considerable data requirements. For such industries, traditional economic 
approaches like presenting technologies in reduced forms (such as aggregated energy intensity) are still valid (Hogan and Jorgenson, 1991). Such an approach attempts to establish the direct relationship between energy intensity and other economic variables. In many cases, such relationships are quantified based on economic theories only and only a few cases are supplemented with econometric results. This is particularly true when it comes to the sub-aggregated industry level or nonOECD countries (one exception might be Pesaran et al., 1998).

This study follows the model of analyzing aggregate energy intensity, but supplements econometric results. As a basis for the econometric estimation, this study first establishes a comprehensive database of energy intensities at the sub-aggregated (ISIC-2 digit) industry level including those data for OECD and non-OECD countries. Then an analysis is carried out using panel analysis, which assures the generality of the result over countries. Such basic substantiation can serve as the foundation of a more sophisticated analysis using quantitative information as an input parameter.

The structure of this paper is the following. Section 2 describes the raw data used in this study, with a detailed discussion on the construction of the energy intensity and industrial end-use energy price data. Section 3 describes the formulation of the model used for the analysis of the energy intensity. Section 4 presents and discusses the results of the statistical estimation. Finally, Section 5 highlights the conclusions of the paper.

\section{Data}

One important aspect of this study is the construction of an industrial energy intensity database and the estimation of average industrial energy prices for different countries. All these data are needed for the panel analysis, where data needs to be comparable over country and over time.

\subsection{Data coverage}

The time period covered in this study is between 1971 and 1996. The total industrial sector is disaggregated into the following ten industries which is the classification that is consistent with the ISIC Revision 2 at the twodigit level. In addition, metal product industry [ISIC 37] and machinery industry [38] are further disaggregated into the three-digit level.

1. Food and tobacco [ISIC 31, in Revision 2].

2. Textile and leather [32].

3. Wood and wood products (other than pulp and paper) [33].

4. Paper, pulp and printing [34].
5. Chemical and Petrochemical [35].

6. Non-metallic mineral products such as glass, ceramics, cement, etc. [ISIC Division 36].

7. Iron and steel [371].

8. Non-ferrous metals basic industries [372].

9. Machinery (Fabricated metal products, machinery and equipment other than transport equipment) $[38$, except 384].

10. Transportation equipment [384].

\subsection{The data sources}

Final energy consumption data is taken from the International Energy Agency (IEA) publication series, Energy Statistics and Balances. The energy unit used is tons of oil equivalents (toe).

The sectoral output value data was constructed using the production index together with the output value of 1990 expressed in current US dollars at a three-digit level and then aggregated into the two-digit level. The value of output in 1990 in domestic currency was converted into US dollars using the average exchange rates from 1990. This value was then multiplied with the production index series. The advantage of using this method is that it avoids the effect of exchange rate fluctuations.

The production index was taken from the Industrial Statistics Database at the 3-digit Classification Level, published by the United Nations Industrial Development Organization (UNIDO). Missing data in this data source have been estimated at the three digit level using the physical production quantity data from Industrial Commodity Statistics published by the United Nations.

Investment data used here is gross capital formation and is taken from the same UNIDO publication. The data is first deflated with the wholesale price index and then the exchange rate from 1990 was applied. Both the exchange rate and wholesale price index were taken from the International Financial Statistics (IFS) database of the International Monetary Fund.

Industrial energy end-use price series were estimated for each country. They are expressed in constant US dollar per toe. When converting the unit from nominal domestic currency into US constant dollar value, the wholesales price index and market exchange rate of 1990 to US dollar were used.

Also, this industrial energy price was calculated as a weighted average of industrial energy prices for four energy carriers: petroleum products, natural gas, coal and electricity. The price for petroleum products was calculated as a weighted average of liquefied petroleum gas (LPG), naphtha, gas/diesel oil and heavy fuel oil. Weights of energy sources in the industrial sector were taken from the Energy Balances and Statistics from the IEA. These weights were then applied to industrial energy prices, which were taken from several data sources. The three basic sources for industrial energy prices were 
Table 1

Average levels of energy intensities for each industry. Index with total average normalized to $100^{\mathrm{a}}$

\begin{tabular}{|c|c|c|c|c|c|c|c|c|c|c|}
\hline & Food & Textile & Wood & Pulp & Chemical & $\begin{array}{l}\text { Non- } \\
\text { mineral }\end{array}$ & Iron & $\begin{array}{l}\text { Non- } \\
\text { ferrous }\end{array}$ & Machinery & $\begin{array}{l}\text { Transport } \\
\text { equip. }\end{array}$ \\
\hline ktoe/billion US\$ & 52,274 & 49,623 & 81,267 & 167,493 & 282,289 & 684,481 & 605,465 & 381,634 & 30,287 & 28,945 \\
\hline Index & 22 & 21 & 34 & 71 & 119 & 290 & 256 & 161 & 13 & 12 \\
\hline
\end{tabular}

${ }^{a}$ Index numbers presented in the bottom row are calculated in such a way that the inter-industry average of the upper row becomes 100 .

Energy Prices and Taxes from the IEA, Energy Indicators of Developing Member Countries of $A D B$ from the Asian Development Bank (ADB), 1992 and Energy, Economic Statistics and Indicators of Latin America and the Caribbean from the Latin American Energy Organization (OLADE). A separate, unpublished document (Miketa, 2000) on the detailed description of the methodology and results is available from the author upon request.

The database thus includes energy intensity data for 84 countries and energy price data for 52 countries. Among them, 39 countries are included in this study. ${ }^{1}$ The country selection was guided firstly by the availability of energy price data and secondly by the availability of investment data. Twenty-one of the 39 countries belong to "developed market economies" as defined by the World Bank classification. The other 18 countries are mainly from Asia and Latin America. Note that in some places, data is incomplete. In these cases, interpolations were used to fill holes with respect to points in time as well as industries.

\subsection{Some descriptive statistics of energy intensity}

Table 1 shows, for all countries included in the database, the average levels of energy intensity, defined as final energy consumption divided by output, expressed in terms of ktoe per billion US dollars for each industry. For reference, the lower row shows the same numbers in terms of the index with 100 being the average of the total industries. The non-mineral products and iron and steel industries are two outstanding energy-intensive industries. Then, non-ferrous metals and chemicals are also regarded as energy-intensive industries. Pulp then comes

\footnotetext{
${ }^{1}$ The countries included are Australia, Austria, Bangladesh, Belgium, Brazil, Canada, Chile, Colombia, Denmark, Finland, France, Germany, Greece, Hong Kong, Hungary, India, Indonesia, Ireland, Italy, Japan, Luxembourg, Malaysia, Mexico, Netherlands, New Zealand, Norway, Pakistan, Philippines, Poland, Portugal, South Korea, Spain, Sweden, Thailand, Trinidad and Tobago, Turkey, United Kingdom, United States, and Venezuela. Additional 13 countries for which energy price data were included in the database, but which are not included in the analysis are Argentina, Bolivia, Cuba, Czech Republic, El Salvador, Jamaica, Peru, Romania, South Africa, Sri Lanka, Switzerland, Uruguay, and Taiwan.
}

as the fifth energy-intensive industry in the ten-industry sample. Wood and furniture, food and tobacco, and textile and leather are less energy-intensive industries. The last two columns of the table list the two hightechnology industries - transportation equipment and machinery. It has to be noted that in some industries, such as transportation equipment and textile and leather, the included number of countries is smaller compared to the other industries ( 25 and 30 , respectively). Data holes were mainly from developed countries, which tend to be energy-intensive. This fact needs to be taken into account when looking at this simple statistics.

As shown in my previous analysis using the same data set, these numbers are characteristic of the industries. Their variability across countries and over time is analyzed in more detail in Miketa (1998). Some of the most important results were: (1) developed countries have lower energy intensities compared to the other countries, but this difference is more pronounced in the non-energy intensive sectors; (2) developed countries show stable energy intensities over the observed period; (3) energy intensities for newly industrializing countries generally show increasing energy intensities; and (4) differences between countries are generally greater than changes within countries over the observed period. ${ }^{2}$

One can argue that value added, rather than output, is a more appropriate measure of economic activity that directly corresponds to the final energy consumption of an industry. However, given the nature of the experiment, in which the change, rather than level, of energy intensity is the dependent variable, fluctuation of intensity should be avoided as much as possible. From this point of view, output seems like a more suitable measure because value added is affected by not only output fluctuation, but also input fluctuation. If the value-added ratio does not vary dramatically among countries and over time, we will use energy intensity valued with the output.

As an illustration to see if the plausibility works, we examine the possible difference between intensity valued

\footnotetext{
${ }^{2}$ Differences between absolute levels of energy intensity should not be over-interpreted because they depend on assumptions about the exchange rate. This point is particularly relevant for Eastern European countries.
} 
Table 2

The level of energy intensity valued with value added. Index with total average normalized 100

\begin{tabular}{|c|c|c|c|c|c|c|c|c|c|c|}
\hline & Food & Textile & Wood & Pulp & Chemical & $\begin{array}{l}\text { Non- } \\
\text { mineral }\end{array}$ & Iron & $\begin{array}{l}\text { Non- } \\
\text { ferrous }\end{array}$ & Transport equip. & Machinery \\
\hline Index & 23 & 18 & 22 & 66 & 124 & 188 & 332 & 208 & 8 & 10 \\
\hline
\end{tabular}

with output and valued with value added. The following table shows the latter in a format comparable with Table 1.

The numbers in Table 2 show quite a similar picture to the ones in Table 1, with the exception of non-mineral industry. From the above calculations, it can be concluded that using the energy intensity valued with output does not cause a serious problem in the analysis, and therefore, we will continue the analysis with this intensity measured with output.

\section{The model}

\subsection{The method of the analysis}

The energy intensity used in this study is defined as final energy consumption divided by sectoral output. The main purpose of the analysis is to study the development of energy intensity over time. Two variables were analyzed with respect to their impact on energy intensity. These were (1) total sectoral economic activity and (2) sectoral investments. In doing so, the panel analysis method was used. The panel analysis method uses pooled sectional and time series data. Pooling cross section and time series gives a very general picture of correlations among variables, at the same time hiding some intercountry differences. The variables have two cross-sectional dimensions, industry and country and one time series dimension. The analysis was performed for each industry separately, so that the country dimension will be the only cross-sectional dimension.

\subsection{The model and variables}

To study the impact of industrial development and energy intensity change, the following equation was formulated. Note that the explained variable is change in energy intensity, rather than the level of energy intensity.

$$
\begin{aligned}
\Delta\left(\frac{E}{O}\right)= & a I+b\left(\frac{O+O_{-1}+O_{-2}}{3}\right) \\
& +c P_{E}+\sum_{i=1}^{39}\left(d_{i} D_{i}\right)+\varepsilon_{i},
\end{aligned}
$$

where $E$ is the final energy demand, $O$ the output, $I$ the gross fixed capital formation, $P_{E}$ the energy price, $i$ the country index ( $i=1-39), D_{i}$ the country dummy that takes one for a country $i$, and zero for other countries.

The above equation was formulated as a fixed-effect model. A fixed-effect model is a common model in panel analysis. It allows different groups of cross sections to have different intercepts. In our case, the fixed effect allows different countries to have different intercepts describing country-specific characteristics of energy intensity increase or decrease, independently of any of three explanatory variables tested here. The coefficients of explanatory variables represent the general relationship between variables over all countries. The above equation is estimated for each industry separately, using the Weighted Least Square method (Generalized Least Square with cross-sectional weights). ${ }^{3}$

The investment in question is not limited to energyspecific investment but contains all fixed capital formation in an industry. Thus, the effect of the investments on energy intensity change can capture one aspect of the effect of industrial development on energy intensity. The effect of the investment on energy intensity change is interesting because investment can be regarded as a carrier of the technological change. Some authors establish the theoretical relationship between productivity growth and investment (Scott, 1989), and also some empirical studies have found a positive relationship between them (De Long and Summers, 1991). Process change, driven by investment, may result also in energy intensity reduction, even though their main aim might be general productivity improvement. In this regard, energy intensity can be treated in an analogous way to productivity. It is expected that such process changes need large investments. A working hypothesis here is that investment induces energy intensity reduction through the improvement of efficiency in general.

\footnotetext{
${ }^{3}$ With the cross-sectional data, it is expected that the variance of countries is quite different (heteroscedasticity). Generalized Least Square (GLS) with weighted cross-sectional weights takes into account such a heteroscedasticity in the errors terms across panel members. Weights given are the Feasible Generalized Least Square (FGLS) disturbance term, which is estimated from a first stage pooled OLS regression. Furthermore, the standard error was calculated using White Heteroscedasticity consistent covariance and so $t$-statistics were also calculated based on this standard error. The covariance is known to be the robust covariance when the heteroscedasticity exists in the error terms (Green, 1993).
} 
Output is expected to characterize different states of industrial development and thereby energy intensity. In order to avoid capturing the direct influence of the short-term output fluctuation, the output is introduced as the three-year moving average. Then the specification relates this absolute output level with the change of energy intensity. The coefficient shows whether the different states of the industrial development suggests differences in the change of the energy intensity. Together with the effect of the investment, one can obtain a picture of the general path of the energy intensity evolution along with the development of an industry represented by the size of output.

The change in the energy price is included as a factor to motivate the carrying out of energy saving programs. We expect a negative coefficient (meaning energy intensity reduction) with respect to a higher energy price. For the purpose of the panel analysis, internationally comparable energy price data was estimated for each country as already described above.

\section{Estimation result}

\subsection{Overall results}

Table 3 presents a summary of the estimated results for each industry. They are shown according to energy intensity from the top to the bottom. Statistical significance is indicated with asterisks. Note that country-specific coefficients for constant terms were also estimated for each country but are not presented here. These constant terms represent country-specific trends of energy intensity increase or decrease over the observed period. The interest here is in a general view that is common over the country concerning the effect of the sectoral industrial development on energy intensity. Therefore, we confine our discussion to the results for the coefficients of the explanatory variables.

What we are interested in is the effect of industrial development at sectoral levels on the energy intensity captured as an investment effect and an output effect. The dependent variable in our specification is a change in energy intensity, rather than absolute level. The positive sign of the investment coefficient represents an increase in the energy intensity in response to an expansion of an industry. As for the output, the positive sign is interpreted in such a way that the more developed
Table 3

The correlation between the change in energy intensity (toe per billion US\$) and investment (100million US\$), output (100 million US\$ threeyear moving average); and change in energy price (US\$ per toe) ${ }^{\mathrm{a}}$

\begin{tabular}{lccc}
\hline & Investment & Output & Energy price \\
\hline Non-metallic products & $\mathbf{- 1 . 8 8 2}$ & $34.975^{* *}$ & $\mathbf{- 3 1 . 4 3 7 ^ { * * * }}$ \\
Iron and steel & $10.803^{* * *}$ & $68.816^{* * *}$ & $\mathbf{- 2 4 . 1 8 7 ^ { * * * }}$ \\
Non-ferrous metals & 0.423 & $34.670^{* * *}$ & $6.933^{* * *}$ \\
Chemical & $0.015^{* * *}$ & $7.01^{* * *}$ & $0.947^{* * *}$ \\
Pulp and paper & $0.446^{* * *}$ & $8.130^{* * *}$ & 0.117 \\
Wood and furniture & 11.196 & $19.122^{* * *}$ & $\mathbf{- 1 . 0 3 5 ^ { * * * }}$ \\
Textile and leather & $0.469^{* * *}$ & $7.227^{* * *}$ & $\mathbf{- 1 . 9 9 5 ^ { * * * }}$ \\
Food and tobacco & $\mathbf{- 0 . 0 7 3 ^ { * * * }}$ & $1.296^{* * *}$ & $\mathbf{- 2 . 9 4 4} 4^{* * *}$ \\
Machinery & $\mathbf{- 1 . 7 7 5}$ & 0.134 & $\mathbf{- 0 . 0 1 9}$ \\
Transportation equipment & 0.084 & 0.292 & $\mathbf{- 3 . 1 5 3 ^ { * * * }}$ \\
\hline
\end{tabular}

a Asterisks show the statistical significance of the estimated coefficient (three asterisks mean significance level $95 \%$, two for $90 \%$, one for $85 \%$, and no asterisk for significance levels below $85 \%$. The cells with bold face correspond to the negative sign of the coefficient.

state of an industry tends to increase the energy intensity.

Now, a very strong result for the output coefficients is found. A strong positive sign for all the branches result, exceptions being only two least energy intensive industries. Nonetheless, they are all statistically significant. Energy price shows, in most cases, the expected negative sign. Two industries were exceptions, chemical and nonferrous metals. As for the investment coefficient, a mixed result was found in terms of signs and statistical significance. However, it at least seems plausible to say that there is little evidence that investment would reduce energy intensity, as anticipated prior to the experiment.

\subsection{The effect of investment}

Let us first take a closer look at the effect of investment on the energy intensity change. The numbers presented in the above table show that energy intensity increase (decrease) corresponds to the investment (US 100 million dollars) made.

In seven industries out of ten, positive coefficients were found. A negative coefficient was found in three industries, with only one industry showing statistical significance. There does not seem to be an apparent relationship between energy intensity and the coefficient of the investment. One commonality is found among the

The average investment between 1971 and 1997 for Developed Market Economy Countries, in US million dollar

\begin{tabular}{lllllllllll}
\hline & Chemical & Food & Machinery & Non-mineral & Pulp & Iron & Textile & Wood & Transport equip. Non-ferrous \\
\hline Million US S & 417.1 & 387.2 & 373.2 & 161.7 & 133.7 & 99.4 & 62.5 & 40.6 & 27.2 & 14.3 \\
\hline
\end{tabular}


industries that show similar coefficients; it is the size of investment of an industry. Table 4 gives an approximate idea about the relative size of investments in each industry. Food and tobacco, and machinery and non-mineral products industries show negative investment coefficients, and together with the chemical industry that shows very small positive coefficients; they constitute the biggest four investment industries in our sample. The smallest three investment industries in our sample, nonferrous metals, transport equipment and wood industries, all show positive but insignificant signs of the investment coefficient.

Insignificant coefficients of investment in industries with a smaller size of investment are reasonable. Results for industries with bigger investments must capture the 'real' effect of the investment. The fact that in those industries the signs of the coefficient were negative seems to support the working hypothesis that investments would reduce energy intensity.

However, in two cases, the negative coefficients were not statistically significant. Moreover, the biggest investment industry, chemical, showed a significant positive coefficient, although it was a small value. In full, it was only the food and tobacco industry that shows the statistically significant negative coefficient for investment. Four industries show positive coefficients with statistical significance, and three additional industries also show positive coefficients, although they were not statistically significant.

The expectation expressed by our working hypothesis that investment would reduce energy intensity was not fulfilled. Therefore, it should be concluded that this was a negative result in terms of our prior expectation. The basis of the expectation was the similarity of the effect of investment on energy intensity to its effect on productivity growth. Investment is a carrier of the technological change, and from that point, analogy to productivity was drawn.

Now we have to turn our attention to the dissimilarity of the energy intensity and productivity. A fundamental difference exists between them, i.e., public motivation. Concerning energy productivity, it also improves as a result of energy improving programs. Interest in energy saving programs can come depending on the pressure of having higher energy prices or stricter environmental regulations. Such energy-saving programs and subsequent reductions in energy intensity may or may not go in line with general productivity improvement depending on the circumstances. Regarding the productivity growth, it can improve either by improving the overall cost or by proving the quality of products. This, again, may or may not go together with the energy intensity reduction. In particular, improving the quality of products often involves sophistication of the production means, which can adversely affect the energy intensity improvement.

\subsection{The effect of output}

One firm result in our experiment was that the developed state of industry indicates the bigger increase in energy intensity. This is found from the positive sign of the coefficients for output to the energy intensity change. Such coefficients were statistically significant for eight industries out of ten. This means that for the same amount of investment carried out in different countries with different status of development, the less developed one would have less increase in energy intensity.

Several reasons for this result can be thought of. One of them could be that energy intensity reduction possibilities would run out as an industry grows. The fact that the coefficients for investment and for output differ in some industries clearly suggests this possibility. In those industries where investment shows negative and output shows positive, it is indicated that the expansion of the industry in the form of the investment associates the reduction in the investment but such reduction possibility would decline as the size of an industry grows.

Another reason for the positive coefficients of output could be the effect of the quality change of what they produce. This is a point that was briefly mentioned in the investment section. Sophistication of the production means looks like the natural course of industrial development, and it is more of energy intensity increase than of energy intensity reduction.

\subsection{Energy prices}

The expected coefficient of energy price was negative reflecting that higher energy prices are likely to stimulate energy intensity reduction. Results for most industries show negative coefficients, thus confirming this expectation. However, two of the most energy-intensive industries came out with a significantly positive sign.

One remark on this opposite sign is that the energy price data was not constructed as an industry-specific energy price. It does not give a satisfactory explanation for the opposite sign, but one can test with more detailed energy price data in a future experiment.

\section{Conclusions}

One of the points of this paper was to examine whether investment, in general not limited specifically to energysaving investment, has the effect of reducing energy intensity. This would suggest that the possibility for energy intensity improvement goes together with industrial development. Our results show, however, that one cannot be optimistic about this effect of investment. Investment in general does not have a natural force to lead to energy intensity reductions. 
Another point of the paper was to analyze how the size of an industry affects the energy intensity change. A clear answer was given on this point; the bigger an industry grows, the more energy intensive it becomes.

With this description of relationships between the development of sectoral energy use and sectoral economic activity, the next step after this study would be to put the model developed here into a comprehensive economic modeling framework, which allows for the evaluation of the $\mathrm{CO}_{2}$ development. For that purpose, COMPASS (Comprehensive Model for Policy Analysis) model developed at Keio University is suitable (Meyer and Uno, 1997 ;Uno, 1998). It has a multi-sectoral framework with 36 industries and world economic activities are linked through trade and investment. With the COMPASS model, the effect of investments from abroad could be analyzed. It also has the advantage of being able to distinguish the structural change of industries in an economy and the change in the sectoral energy intensities when analyzing the energy use at a macroeconomic level.

\section{Acknowledgements}

I am extremely grateful to Dr. Dirk Vanwynsberghe for his encouragement and helpful comments. My personal thanks also goes to Professor Uno, who has supported me as my Ph.D. supervisor.

\section{References}

Asian Development Bank, 1992. Energy Indicators of Developing Member Countries of ADB.
De Long, B.J., Summers, L.H., 1991. Equipment investment and economic growth. Quarterly Journal of Economics 106, 445-502.

International Energy Agency. Energy Statistics and Balances. Various years.

International Energy Agency. Energy Prices ad Taxes. Various years. International Monetary Fund. International Financial Statitstics. Various years.

Green, W.H., 1993. Econometric Analysis, 3rd Edition. Prentice-Hall International, London.

Hogan, W.W., Jorgenson, D.W., 1991. Productivity trends and the cost of reducing $\mathrm{CO}_{2}$ emissions. Energy Journal 12 (1), 67-85.

Latin Ameirican Eergy Organization (OLADE). Energy, Economics Statistics ad Indicators of Latin America and the Carribeam. Various years.

Messner, S., Strubegger, M., 1995. User's Guide for MESSAGE III, WP-95-69. International Institute for Applied Systems Analysis, Laxenburg, Austria.

Meyer, B., Uno, K., 1997. The theoretical structure of the internationally linked dynamic input-output-model. COMPASS. Paper Presented at the Fifth INFORUM World Conference, Italy.

Miketa, A., 1998. International energy intensity comaprison for manufacturing sectors. Paper presented for the Pan Pacific Association of Input-Output Studies, Tokyo.

Miketa, A., 2000. Technical note on the construction of the industrial energy price data. COMPASS Project Mimeo, Leiuven, Belgium.

Pesaran, M.H., Smith, R., Akiyama, T., 1998. Energy Demand in Asian Developing Economies. Oxford University Press, Oxford.

Repetto, R., Austin, D., 1997. The costs of climate protection: a guide for the perplexed. World Resource Institute.

Scott, M., 1989. A New View of Economic Growth. Clarendon Press, Oxford.

United Nations. Industrial Commodity Statitics. Various years.

United Nations. Industrial Development Organization (UNIDO). Industrial Statitstics Database at the 3-digit Classisfication LevelI. Various years.

Uno, K., 1998. Policy application of global economy-energyenvironment (3E) accounting and modelling. Paper to be presented at the International Input-Output Association Meeting, New York. 
